\title{
Women's Online Driver in Patriarchal Culture
}

\author{
Nur Hidayah ${ }^{1}$, Grendi Hendrastomo ${ }^{2}$, AdiCilik Pierewan ${ }^{3}$ \\ ${ }^{123}$ Sociology Education Department, UniversitasNegeri Yogyakarta \\ 1'nur_hidayah@uny.ac.id, ${ }^{2}$ ghendrastomo@uny.ac.id, ${ }^{3}$ adicilik@uny.ac.id
}

\begin{abstract}
Online driver is an alternative work in the informal sector. The informal sector is able to accommodate workers without a complicated selection process, not require large capital and high skills. Women, who become online drivers, are seen socially different due to the dominance of a strong patriarchal culture. This study aims to reveal the social position of women online motorcycle taxi drivers amid the dominance of a patriarchal culture. Besides that, it also reveals the opinions of men and the public in seeing the female profession as online motorcycle taxi drivers. This study used a qualitative method with descriptive analysis. It used to obtain a clearer picture, to explore data through indepth interviews, to meet the objectives of this study. The results showed that the families objected when women become an online driver. However, for economic reasons, the family can give permission for women to works. Interestingly, when women work as online motorcycle taxi drivers, they often receive unequal treatment when meeting male consumers. Men feel uncomfortable when ridden by women. men feel stronger and they should piggyback on women. Men also feel that women should only be at home, taking care of children and doing everything at home. Women should not work and earn a living, especially by being an online motorcycle taxi driver. Compared with man, users of online motorcycle taxi services see that women are more careful and gentler in service. Women are seen by society as individuals who are more involved with the emotional and maternal side. This condition shows that the position of women is still subordinate in the patriarchal cultural structure in society.
\end{abstract}

Keywords: Women driver, Patriarchal, Ojek Online

\section{Introduction}

Women are portrayed as figures who are solely concerned with household domestic affairs like kitchen, children, shopping, etc. So far, the labeling attached to women is a weak, not as strong as men, causing various gender injustice problems. Perspective of Javanese society for examples women are identically with 3M (touch up, be a mother, cooking). Today, it is not a surprise that there are women working outside. In addition to meeting family needs, work can also be used as an arena for self-actualization. This can also be seen in women who become online motorcycle taxi drivers. Online motorcycle taxis as an alternative mode of transportation are widely preferred in various circles. Besides the easy access to ordering, it is also very affordable in terms of rates. So that online motorcycle taxi users come from various generation. Online motorcycle taxi is an alternative job in the informal sector. The informal sector is able to accommodate workers without a complicated selection process, and does not require capital and high skills. 


\section{Research Method}

This study used a qualitative method with descriptive analysis. It used to obtain a clearer picture, to explore data through in-depth interviews, to meet the objectives of this study.

\section{Result and Discussion}

\subsection{The Factors behind women working as online motorcycle taxi drivers}

There are many factors behind women as online motorcycle taxi drivers:

\section{a) Meeting Needs}

The lack of employment opportunities and the increasing necessities of life, as well as the high cost of renting a place to live in Yogyakarta make it an economic challenge that must be faced by individuals living in Yogyakarta. This is no exception for women who live in Yogyakarta. Online motorcycle taxis are one of the jobs that offer income to meet their daily needs.

The informants said that the reason for being an online motorcycle taxi driver is to fulfill their daily needs. It can be concluded with statements from the informants that being a female online motorcycle taxi driver really helps them meet their daily needs. It is undeniable that in life, the main thing in human life is the fulfillment of basic needs and being able to survive. Needs that must be fulfilled every day include: eating, drinking and a proper place to live, and other necessities.

\section{b) Flexible Working Time}

Online motorcycle taxi jobs offer a flexible working system. This means that online motorcycle taxi drivers can start and end work at any time in one day. So in determining work, online motorcycle taxi drivers are free to allocate work time. Unlike working tied to one agency, being an online motorcycle taxi driver, there is no division of shifts or an obligation to work in one day. It is common for them to make this online motorcycle taxi job their side job to fulfill their needs life in Yogyakarta. The informants started their work while relaxing at home by activating the service. This is beneficial for them because being a female online motorcycle taxi driver can freely work and are not tied to a system.

\section{c) No Target at Work}

Jobs in companies or official institutions often have a standard that will be achieved in one time. Those system makes workers uncomfortable and getting pressure in carrying out their work. The job of being an online motorcycle taxi driver is a suitable choice for individuals who make their main job but want a work system that is regulated by themselves. It means, when becoming an online motorcycle taxi, it is very different from other jobs in the work system.In ordinary company, the work system and the targets to be achieved in one period of time have also been set. The advantage being online motorcycle taxi jobs for female, they can share their time with household tasks that are burdened for them. 


\section{d) Income}

High income encourages people to work as online motorcycle taxi drivers. People are tempted by the income they get as an online motorcycle taxi driver. Especially when the income system from being an online motorcycle taxi is paid every day, in contrast to jobs that are tied to institutions or agencies. So with the salary offer that you will get every day, making a job as an online motorcycle taxi driver is one of the jobs that you are currently looking for. Such as the admission of our informants who stated that the income from becoming an online motorcycle taxi is classified as a good income.

The average income of informants per day can get IDR 200.000. Their income determined based on the number of orders that come in a day. So in one day, you will get high incentives and income if the drivers can complete some orders depending on minimum requirement set by company. If we try to convert in one month, around five million can be earned become online motorcycle taxi drivers. Those salary is high and very promising for someone compared to theregional minimum salary scale in 2020, around IDR 2.004 .000 per month.

\subsection{The position of women's online driver in patriarchal culture}

Being a woman online motorcycle driver has a big risk, they have to operate a motorized vehicle and deliver someone or something to their destination. The Indonesian people still see a matter relating to automotive are considered to describe the inherent traits of men who have strong, manly and mighty characteristics while women are the opposite. With the presence of online motorcycle taxis as a job for women in Yogyakarta, there are also obstacles in their daily work while working.

\section{a) Got teased by a male passenger}

Female online drivers are more prone to receiving orders from a man, which is prone to sexual harassment. The view of society that still considers women as gentle and helpless makes men often sexually harass female drivers by teasing, praising excessively, and even physical contact that leads to sexual harassment. This is a threat that hinders their work as online motorcycle taxi drivers. There are some informants who don't want to activate the application service anymore because they are afraid of getting men passengersagain.

\section{b) Getting yells and pity from male passengers}

Female online motorcycle taxi drivers have also received yells from male passengers, because they are considered slow in driving, but on the other hand, they also get pity from male passengers so they take the initiative to replace female online motorcycle taxi drivers to become their drivers in front. The thing that most often happens is the initiative of male passengers to change the driving of the motorbikes of the female drivers.

\section{c) Getting stigma}

Most of the female online motorcycle taxi drivers get permission from their family to work. However, there are still people's views that give a negative stigma to them. There are still parts of their family who perceive women who become online drivers, because they are considered men's jobs. Even, in reality, the income from online motorcycle taxis is very helpful in meeting the daily needs of the family. 
Likewise, the response of male online motorcycle taxi drivers, they stated that women should be at home taking care of children and housework. Women who drive online motorcycle taxis are considered unsuitable because the job belongs to men because it requires lot of energy and strong physic.

Women are seen as individuals who are more involved with the emotional and maternal side. So, it is true that they have been proven about the services provided to them when ordering online motorcycle taxi services.

Hardvard model of gender analysis technique used in this study, designed as a basis for seeing a gender profile of a social group. The Hardvard model framework is composed of three main elements, namely: an activity profile, an access profile and a control profile (Handayani, 2001). The following are gender analysis techniques in this study which are in accordance with Hardvard analysis techniques.

\subsection{Activities of women online motorcycle taxi drivers (activity profiles)}

The profile of the activity and division of work in the families of women who become online motorcycle taxis includes public activities (earning a living), domestic activities (activities in the household), and social activities.

\section{a) Public Activities}

Women's activities that are used as a source of economic and family income for women regarded as public activities. The activity as the main source of the informants' economy in this study is the work income of women online motorcycle taxi drivers. The following table shows the time allocation for women online motorcycle taxi drivers working.

\begin{tabular}{ccc}
\multicolumn{3}{l}{ Table1.Time allocation for Women's Online Driver } \\
\hline No & Name & Time Allocation per Day \\
\hline 1 & $\mathrm{Sc}$ & 12 hours \\
2 & $\mathrm{An}$ & 10 hours \\
3 & $\mathrm{Vr}$ & 12 hours \\
4 & $\mathrm{Wr}$ & 9 hours \\
5 & $\mathrm{Wt}$ & 12 hours \\
\hline
\end{tabular}

From the table shows that female online motorcycle taxi drivers work between 9 hours and 12 hours a day. It shows that becoming women's online driver is their main daily job. The narrative from informant showing that female online driver who are not married by working as online motorcycle taxi drivers can meet their needs while living in Yogyakarta to pay for boarding houses or pay for their daily needs.

It is the same with three other informants who are married, namely $\mathrm{Vr}$, Wn and $\mathrm{Wt}$, that they become online motorcycle taxi drivers to fulfill their needs, help the family economy, and meet children's educational needs. Especially for $\mathrm{Vr}$, who is the backbone of the family and makes online motorcycle taxi work her main income to fulfill her daily needs. The interview with Wr stated that their husband supports their work as online driver to complete their unfixed salary and can support family needs. Unstable husband's income made her involved in finding additional income to meet their family needs. To meet the needs of life and support the family economy, informants are involved in public activitiesby working as 
online motorcycle taxi drivers. Based on the involvement of women in meeting needs and helping the family economy, it can be said that the public activities of women online motorcycle taxi drivers running continuously.

\section{b) Domestic Activities}

Working as online driver do not disturb their domestic activity. The flexibility workhours help them to maintenance with their domestic activities. From the interview show that Sc andAn, as single, can share their domestic activities more freely because they are still not married.It turns out to be the same as $\mathrm{Vr}, \mathrm{Wr}$ and $\mathrm{Wt}$, who are already married and have children,they can manage their domestic activities with make prioritize homework before they start work as online motorcycle taxi drivers.It can be seen that the informants have an active involvement in domestic activities carried out before and after working as online motorcycle taxi drivers.

In building gender harmony and equality, it is necessary to establish a balanced principle in the division of labor between husband and wife. There is a relationship that does not differentiate between gender in the division of labor, but rather on the need for the availability of time devoted to all jobs in the domestic sector. Those the position of women as wives or mothers in the family will be equal to other family members, because all family members are involved in domestic activities. Although there is no definite division of duties for domestic work, the husband also finally understands his wife's condition by helping with household chores such as helping with washing clothes, ironing, cleaning the house, etc.

For the women, when they act as wives and mothers who work in the public sector, before leaving for work they have to complete tasks at home first. So that, when all family members are involved in domestic activities with a pattern of division of labor that does not differentiate gender, it is very possible for cooperation between family members. This condition is one of the strategic efforts for the position of women in the family.

\section{c) Social Activities}

In carrying out social activities, women onlinedrivers are also involved in it. Community activities carried out by women motorcycle taxi drivers online such as, social gathering, attending weddings, and others. So when they carry out social activities, female online motorcycle taxi drivers will stop and turn off their online ojek service. From the informants, there are differences, Sc and andAn who live in a boarding house, making them not participate in social activities. In contrast, $\mathrm{Vr}, \mathrm{Wr}$ and $\mathrm{Wt}$, divide their time for following social activities in their neighborhoods. It means that not all women online driver can participate in social activitiesdue to the fact that female online motorcycle taxi drivers are more often spent doing their jobs compared to social activities in the community. They mostly prefer to work to fulfill their needs.

\subsection{Time Allocation in Public and Domestic Activities}

Allocation of time in public and domestic activities is an activity where women, both married and single, share their time between taking care of domestic household activities and working as an online motorcycle taxi driver. According to informant, being an online motorcycle taxi driver is more flexible to manage time between taking care of domestic affairs at home and working as an online driver. There is a different pattern when women are married 
with single women. On married women, they start their job as online driver every day after they have finished taking care of household.

Their daily activities begin with getting up earlier than other family members to do household activities such as cooking, washing clothes, taking care of children, etc. After their children are ready to go to school, female online motorcycle taxi drivers drive their children to school while they go to work as online motorcycle taxi drivers.Otherwise, single women who drive online motorcycle taxis tend to be more flexible and freer to share their time between domestic and public activities. Thedifferences is the absence of dependents such as cooking for the family and sending their children to go to school. So their time is more flexible in starting and ending their work as online motorcycle taxi drivers.

\subsection{Economic Resources of Women Ojek Drivers online (Access Profile)}

The access profile is an opportunity for women to take advantage of family resources without feelings and attitudes blocking each other. The economic resources of women online motorcycle taxi drivers are delivery services for people and goods. The results of this study indicate that the access profiles of women online motorcycle taxi drivers have access to education for children, clothing, food, shelter or other needs to support the family economy.For women online drivers, who are married,has other obligations that must be carried out. There is an agreement with their husbands to work together for economic stability in the family.

On the other hand, single women online driver get access to economic resources for personal gain wider, because they still do not have a family and only fulfill their daily needs for themselves for clothing, food and shelter while living in Yogyakarta.

\subsection{Control Profiles (Decision Making and Norms)}

The control profile in this study has the meaning of women's authority in making decisions on the use and outcomes of the utilization of existing economic resources. In other words, the control profile is the decision making between men and women in controlling the use of resources needed to perform household tasks (Handayani, 2001). Resources can be in the form of material, (economic, political, social and time value), access to the use and control of resources and then grouped according to gender, then the factors that influence the things that result in the division of labor, the existence of profile of access and control in a family of female online motorcycle taxi drivers.

In relation to the control profile, it is necessary to distinguish betweendecision making (decision making) and decision making (decision taking). In making family decisions between men and women, it is necessary to pay attention to the norms that control the relationship between husband and wife. In societies that adhere to a patriarchal system, decision-making is still centered on the husband (male). The husband's role is very strong in patriarchal culture because they are considered the head of the family so that all decisions must be in the hands of men.

There are three things that must be in the decision-making process in the family, namely a process of interaction carried out by husband and wife, how the decision is taken, to who decides (Harmona, 2001). Taking advantage of the economic outcomes of the family in this study is that the family of women online driverdependson their husband policies. Man is the head of the family who is responsible for whatever happens in the family. In some women 
online driver family, decision making is done through a joint discussion mechanism including in determining women's job to support economy of their family.

The condition of the family among Indonesian family depend on the man who is the backbone of the family. An uncertain husband's income causes the family's economic income to be unstable. Besides that, if they depend on their husband's income, they will not be sufficient for their daily life. In this case when women get jobs, the compensation they get can support family needs. Although women get jobs, the decision to use the money must be made with the husband's knowledge. So women's do not have autonomy with their self.

Family economic limitations result in very limited access and control over the use of family economic resources. In addition, the husband's dominance in making decisions also limits the access and control of the wife in the family. In contrast to informants who is single, they can use their work to fulfill their daily needs independently. So in terms of access to and control over economic use, unmarried female online motorcycle taxi drivers tend to have personal autonomy. There is no domination from the partner, especially in making decisions in sharing the work obtained from online motorcycle taxis.

\section{Conclusion}

The existence of female online motorcycle taxi drivers in a patriarchal culture experiences inequality. Most of them receive unequal treatment, especially from male passengers, male motorcycle taxi drivers, their families and the community. The family objected that women work as online motorcycle taxi drivers. Even so, the family still allows it because it can help the family economy. From the point of view of male motorcycle taxi drivers, sympathize with female online motorcycle taxi drivers because this job requires great strength and strong physical strength. It is thought that women should only take care of children and take care of everything at home. There is an impression that they have the heart and pity because they consider working as an online motorcycle taxi to be a tough and risky job. The existence of discriminatory treatment and harassment among women online motorcycle taxi drivers shows that the position of women is still subordinated in the structure of a patriarchal culture.

\section{References}

[1] Handayani, TrisaktidanSugiarti. 2001. KonsepdanTeknikPenelitian Gender. Malang: PusatStudidanKemasyarakatanUniversitasMuhammadiyah Malang.

[2] Harmona, D. (2001). PergeseranPolaRelasi Gender di KeluargaMigran. Yogyakarta: GalangPrintika 